\title{
A biblioteca pública no contexo da sociedade da informação
}

Emir José Suaiden

Professor do Departamento de Ciência da Informação e Documentação da Universidade de Brasília e-mail:emir@unb.br

\section{Resumo}

Desde o período colonial, as bibliotecas públicas brasileiras pouco contribuíram para a democratização do acesso à informação. Na sociedade da informação, o papel da biblioteca pública passa a ser de vital importância na medida em que pode se tornar o grande centro disseminador da informação, atuando principalmente para diminuir as desigualdades existentes na socialmente injusta sociedade brasileira. Já que não conseguiu "ser tudo para todos", a biblioteca pública pode segmentar o mercado e oferecer produtos e serviços racionalmente estruturados de acordo com as necessidades informacionais da comunidade.

Palavras-chave

Biblioteca pública; Sociedade da informação.

\section{The public library in the context of the information society}

\begin{abstract}
Since the colonial period the Brazilian public libraries have little contributed to the democratization of the access to information. In the Information Society, the public library role takes up a vital importance to be again the great center for disseminating information, and, mainly, for disseminating the existing disparities in the socially injust Brazilian society. Since it was unable to "to be all for all", the public library can segment the market and offer rationally structures products and services, in accordance with the community information needs.
\end{abstract}

\section{Keywords}

Public library; Information society.

\section{A CULTURA DA INFORMAÇÃO}

Historicamente o acesso à informação no Brasil sempre foi definido pelo poder aquisitivo. Durante o período colonial, os jesuítas fizeram grande esforço para facilitar o acesso à palavra escrita. Na verdade, foram esforços isolados, pois a educação e a cultura não eram prioridades dos segmentos dominantes do poder.

A vinda da Biblioteca e da Imprensa Real também não representou indicadores efetivos do acesso e da disponibilidade de informação para toda a sociedade. No entanto, no dia 5 de fevereiro de 1811, Pedro Gomes Ferrão de Castello Branco encaminhou um projeto ao governador da Capitania da Bahia, solicitando a aprovação do plano para a fundação da Biblioteca. Esse documento, que historicamente é o primeiro projeto na história do Brasil com o objetivo de facilitar o acesso ao livro, mostrava grande preocupação com a área da educação. O plano foi aprovado, e a Biblioteca inaugurada no Colégio dos Jesuítas em 4 de agosto de 1811. Posteriormente, todas as providências para a fundação de bibliotecas partiram sempre da iniciativa governamental.

Logo após o período acima referido, inúmeros governos estaduais tomaram a iniciativa de criar bibliotecas estaduais. A biblioteca era legalmente criada por um decreto estadual, no entanto a falta de visão dos administradores era grande, pois geralmente não havia previsão da infra-estrutura necessária. Locais improvisados, acervo desatualizado e composto de doações, instalações precárias, carência de recursos humanos adequados etc. eram as características dessas instituições chamadas bibliotecas. $\mathrm{O}$ ônus da imagem dessas instituições provocou um retraimento do possível público usuário. A imagem passou a ser negativa, pelo povo e eram comuns as afirmações de que se tratava de um local de castigo ou para uma pequena elite composta de eruditos. 
Lima Barreto (1976), escritor social oriundo da pequena classe média suburbana do Rio de Janeiro, retratou em suas obras cenas quotidianas da República Velha. Em meio a um diálogo sobre a "loucura de Policarpo Quaresma”, há essa notável passagem:

“- Nem se podia esperar outra coisa, disse o Dr. Florêncio. Aqueles livros, aquela mania de leitura...

- Por que ele lia tanto? Indagou Caldas (...). Ele não era formado, para que meter-se com livros? (...). Isto de livros é bom para os sábios , para os doutores (...).

- Devia até ser proibido (...) a quem não possuísse um título acadêmico ter livros.. Evitam-se assim essas desgraças."

De fato, tanto na República Velha como na Primeira República, biblioteca era sinônimo de livro. Dificilmente poderia ocorrer a uma pessoa procurar a biblioteca sem estar interessada na informação bibliográfica, e esse é um grande contraste, pois no período mencionado o ensino era muito precário e grande percentual da população era composto de analfabetos. Portanto, era um clima ideal para a disseminação de informação oral, utilitária ou sobre cidadania.

Em 1912, a Biblioteca Nacional passou a ministrar cursos para a formação de bibliotecários. Era fácil perceber a preocupação com a preservação do material impresso. A idéia de disseminação viria muito tempo depois. As bibliotecas criadas nesse período já buscavam um modelo de serviço bibliotecário. $\mathrm{O}$ modelo basicamente era uma cópia do utilizado nos países desenvolvidos na época. Portanto, era um modelo reflexo, baseado em uma realidade que não era a do povo brasileiro.

A preocupação com uma cultura nacionalista aflorou, e em 1922, na Semana de Arte Moderna, os intelectuais passaram a criticar o modelo importado e a buscar uma cultura mais compatível com a realidade brasileira.

Em 1926, foi inaugurada a Biblioteca Pública Municipal Mário de Andrade, que se transformou em marco importante da cultura brasileira e um exemplo para a América Latina. Sua primeira diretora, Adelpha de Figueiredo, foi uma das primeiras bibliotecárias brasileiras, formada pela Universidade de Colúmbia, em Nova Iorque. Rubens Borba de Moraes foi o segundo diretor (período de 1935-1943), e a ele deve a Biblioteca sua reorganização, cujo plano foi dividido em quatro pontos. Primeiro, a reorganização completa dos serviços técnicos. Segundo, a adoção de esquema de expansão bibliotecária. Terceiro, a formação de pessoal habilitado. Finalmente, o quarto, que privilegiava a cooperação com outros institutos.

Uma das características é que essas instituições na época trabalhavam individualmente, sem nenhum esquema de cooperação bibliotecária, o que prejudicava essencialmente a assistência ao usuário.

Sem contar com uma indústria editorial e sem bibliotecas infantis, escolares e públicas para a formação de um público leitor, gerações e gerações foram formadas utilizando como cultura da informação o gate keeper e o colégio invisível, entre as classes elitizadas, e, entre a classe menos favorecida, a informação oral era obtida na Igreja, na escola e entre os líderes comunitários.

No período de 1930 a 1945 , durante a Era Vargas, houve grande necessidade de crescimento e surgiu um surto industrial criando uma nova faixa social que era dos operários. Junto com o Dasp, foi criado o salário mínimo e a Usina Siderúrgica de Volta Redonda. Isso propiciou a criação de companhias de produção de motores, caminhões, aviões e todo tipo de rudimento de uma sociedade industrial.

Em 1937, o Governo Vargas criou o Instituto Nacional do Livro, com a finalidade de propiciar meios para a produção, o aprimoramento do livro e a melhoria dos serviços bibliotecários. Mário de Andrade (1939) assim se expressava a respeito do assunto: "A criação de bibliotecas populares me parece uma das atividades mais atualmente necessárias para o desenvolvimento da cultura brasileira. Não que essas bibliotecas venham resolver qualquer dos dolorosos problemas da nossa cultura, o da alfabetização, o da criação de professores do ensino secundário, por exemplo... Mas a disseminação, no povo, do hábito de ler, se bem orientada, criará fatalmente uma população urbana mais esclarecida, mais capaz de vontade própria, menos indiferente à vida nacional. Será talvez esse um passo agigantado para a estabilização de uma entidade racial, que, coitada, se acha tão desprovida de outras forças de unificação" .

Historicamente, a criação do Instituto Nacional do Livro deve-se a dois fatos. $O$ primeiro era uma resposta do governo federal aos intelectuais que haviam participado da Semana de Arte Moderna e que criticavam muito a administração pela falta de uma política cultural. O segundo fator era que havia necessidade de dar especial atenção à nova classe dos operariários, pois basicamente a mão-de-obra não era qualificada e o analfabetismo atingia altas proporções nesse segmento. 
Logo após a criação do Instituto Nacional do Livro, começaram a surgir críticas sobre a sua viabilidade. De fato, não era fácil propiciar meios para a produção e o aprimoramento do livro. $\mathrm{Na}$ área editorial surgiam os primeiros esforços com Monteiro Lobato, a Companhia Editora Nacional, a José Olympio e outros. O livro era visto como um grande risco editorial. Não havia também parques gráficos. A maioria dos autores fazia sacrifícios para pagar a edição, e o sistema de distribuição era concentrado no eixo Rio-São Paulo.

Outro grande problema era compatibilizar as prioridades governamentais na área da cultura e o interesse das editoras privadas. Assim sendo, as primeiras propostas da administração eram reeditar os clássicos portugueses e brasileiros no intuito de preservar a memória bibliográfica brasileira. As edições sucessivas da Coleção de Documentos Brasileiros eram a comprovação desse fato. No entanto, as editoras privadas tinham outros objetivos, e o principal era tornar o livro uma atividade empresarial de preferência independente das atividades governamentais.

No duelo travado entre as preferências editoriais faltava um diagnóstico sobre o comportamento do leitor real ou potencial no Brasil. Alguns editores passaram a ter como linha editorial o livro didático ou de texto, que, além das facilidades propiciadas pelo governo, tinham um público interessado. Assim sendo, a linha editorial não era baseada em preferências do grande público, mas sim em áreas que tinham um público definido.

Era normal que, nessas circunstâncias, a área cultural fosse prejudicada e com isso o próprio livro cultural e a biblioteca pública. Do outro lado ganhava força o livro didático e o livro texto. Apesar de contar com uma soma maior de recursos na área educacional, a biblioteca escolar nunca foi uma institutição privelegiada no referido processo.

Problemas na fabricação do papel e celulose, falta de parque gráfico, poucas editoras com qualificação para a produção de livros de qualidade, sistema arcaico na distribuição de livros com um pequeno número de livrarias em todo o território nacional e, principalmente, a falta de um público leitor eram as principais características do incipiente panorama editorial do Brasil. Não era mais um órgão governamental que, como em um passe de mágica, poderia transformar a referida situação.

Se de um lado era extremamente difícil incentivar o desenvolvimento da indústria editorial, muito mais difícil era propiciar os meios adequados para a melhoria dos serviços bibliotecários. A primeira pergunta óbvia era saber que tipo de serviços bibliotecários, porque era impossível, pela falta de recursos humanos e financeiros, privilegiar indiscriminadamente todos os tipos de bibliotecas, como infantis, escolares, públicas, universitárias e especializadas.

Nesse estudo de prioridades para o desenvolvimento de serviços bibliotecários, ficou comprovada uma tendência de que as bibliotecas especializadas e centros de documentação que começavam a ser criados tinham mais recursos que os demais tipos de bibliotecas. Era uma grande inversão de valores na medida em que as bibliotecas infantis, públicas e escolares, que deveriam priviligear a formação do leitor, não contavam nem com recursos humanos, nem com recursos financeiros adequados.

A desordem era geral, pois não havia dados e diagnósticos para apontar a situação catastrófica da indústria editorial e dos serviços bibliotecários. O Guia das Bibliotecas Brasileiras demorou a sair e, quando foi publicado, mostrou a triste realidade nacional: bibliotecas deficientes, acervos desatualizados, falta de recursos humanos e monstruosa quantidade de livros que não eram acessíveis aos leitores, pois não foram preparados tecnicamente.

Não havia uma liderança nacional que pudesse demonstrar na época qual o sistema de processamento técnico que era compatível com a realidade brasileira. Como todos eram importados, os técnicos tomavam decisões sem consultar os poucos usuários que geralmente achavam a catalogação e a classificação muito burocráticas. A Biblioteca Nacional, por falta de recursos adequados, não exerceu uma liderança adequada na disseminação de metodologias adequadas que pudessem ter um efeito multiplicativo e assim ser compartilhadas por outras bibliotecas brasileiras.

No referido período, era necessário que a instituição biblioteca fosse dedicada à propagação de uma política de leitura. Mas a preocupação predominante era a preservação do material bibliográfico, e muitas se negavam a fazer o empréstimo domiciliar com receio de o livro ser furtado, e assim o profissional teria de dar conta do material permanente. O livro não era somente associado a material permanente, como era também um símbolo de status intelectual do seu proprietário. Era comum encontrar livros encadernados nas salas de visita. A encadernação era outro valor atribuído à preservação eterna do livro. Por isso, a idéia do livro descartável ou de consumo demorou muito a chegar ao Brasil. 
A outra questão crucial era a questão do leitor. Como se forma um público leitor em um país com problemas educacionais e culturais emergentes que refletiam alto percentual de analfabetismo e desnutrição infantil? E ainda mais: onde as bibliotecas eram vistas como um local de castigo para os estudantes? Richard Bamberger (1977), ao analisar as razões por que em certos países se lê muito mais que em outros, viu que estas se revelaram nos seguintes fatores: $1^{\circ}$ ) a posição do livro na escala de valores do país, tal como se expressa através dos gastos econômicos destinados à promoção do livro; $2^{\circ}$ ) a tradição cultural; $3^{\text {ㅇ) }}$ as oportunidades de leitura; $4^{\circ}$ ) o papel representado pelos livros nas escolas e no sistema educacional.

Os gastos econômicos na promoção do livro são mais ou menos recentes nas atividades culturais brasileiras. $\mathrm{Na}$ década de 30 a 50, o governo promovia a edição e distribuição do que considerava patrimônio bibliográfico. Depois, passou a investir muito no livro didático para distribuição gratuita aos alunos da rede de ensino público. Nesse sentido, não foram raras as práticas desonestas na seleção dos livros a serem adotados. No aspecto relativo à tradição cultural, como já foi visto tanto no período de colonização, como na primeira República, o livro não foi considerado um instrumento valioso de disseminação cultural. As oportunidades de leitura eram raras, a falta de bibliotecas públicas associada ao custo do livro fazia com que a formação do leitor fosse sempre adiada. O papel representado pelos livros nas escolas e no sistema educacional foi sempre um papel secundário, pois não havia bibliotecas escolares, grande parte dos professores era leiga e o que prevalecia sempre era a cópia a dicionários e enciclopédias.

A falta de bibliotecas escolares fez com que os alunos se utilizassem das poucas bibliotecas públicas existentes. À medida que esses alunos ocupavam os assentos das bibliotecas públicas em sua maioria, houve um retraimento da população adulta, ou seja, ocorreu o fenômeno da escolarização da bilioteca pública, que passou a dar prioridade para o atendimento estudantil em detrimento a outros segmentos da comunidade que também necessitavam dos serviços bibliotecários. Os recursos humanos existentes nas bibliotecas públicas atendiam aos estudantes, e os recursos financeiros existentes eram aplicados no livro didático e na compra de dicionários e enciclopédias. Portanto, de pública a biblioteca só tinha o nome, já que a prioridade, por força das circunstâncias, era aplicada no processo educativo. E muito mal aplicada, diga-se de passagem, pois o responsável, ou, raramente, o profissional da informação, não tinha habilidades para orientar a pesquisa bibliográfica e acabava sempre fomentando a cópia aos dicionários e enciclopédias, sem nunca privilegiar uma pesquisa bibliográfica eficiente ou se utilizar de programas de diversificação da leitura.

Como não havia indicadores que comprovassem a eficiência dessas bibliotecas, o responsável se valia de dados estatísticos provenientes de número de leitores e número de consultas e empréstimos domiciliares. Esses relatórios, geralmente mal elaborados, davam a falsa impressão de eficiência em um modelo de atendimento ao público cada vez mais deficiente.

Era normal e até compreensível que o acesso ao livro não fosse uma preocupação governamental. O governo estava mais preocupado em construir escolas, formar e contratar professores. A biblioteca escolar passava desapercebida no processo de ensino-aprendizagem. Falta de livros, de profissionais e de uma consciência sobre a leitura fazia a biblioteca escolar ser sempre incluída nas últimas prioridades.

Assim sendo, os professores que foram formados principalmente por escolas normalistas não tinham nenhuma vocação para a leitura ou para formar leitores conscientes da realidade do país. As comunidades e as famílias exigiam escolas, e a biblioteca não fazia parte da estrutura organizacional da escola.

Pior que não contar com biblioteca escolar era a formação de depósito de livros desatualizados que criaram para a biblioteca uma imagem de lugar de castigo e de mofo. Nesse clima, muitas gerações foram formadas, utilizando apostilas e textos mal elaborados sem nenhuma repercussão sobre a teoria e a prática escolar.

A reforma do ensino, elaborada seguidas vezes na história brasileira, nunca deu prioridade à questão da leitura e da biblioteca. As famílias que possuíam melhor poder aquisitivo adquiriam os livros que consideravam importantes no processo de educação dos seus filhos.

Se a imagem da biblioteca era de lugar de castigo e de punição, o livro tinha uma imagem de instrumento de elitização por causa do custo. As pessoas colocavam os livros nas salas de visitas para demonstrar que tinham conhecimento e eram consideradas intelectuais. Ter livros era sinônimo de ter poder e conhecimento. O livro era para ser preservado, e não consumido. 
Quando os Estados Unidos da América do Norte criaram, com o pocket books, o conceito de livro descartável, isso causou um impacto grande na cultura brasileira, pois feria a rotina de encadernar livros para preservá-los. O próprio governo instituiu o conceito de que livro deve ser considerado como material permanente, e não descartável ou como material de consumo. Essa determinação fez com que as bibliotecas demorassem a realizar o empréstimo domiciliar, pois temiam a nãodevolução dos livros e as penalidades estabelecidas para o responsável pela biblioteca.

Somente na década de 70 é que surgiram os primeiros estudos e pesquisas relacionados com os usuários. Até então, eles não participavam do processo de tomada de decisão e não eram ouvidos pelos profissionais da informação. Na década de 80, levantamentos comprovaram que a faixa de usuários era pequena e que o importante na política bibliotecária era atingir a grossa fatia dos não-usuários. Começam os primeiros estudos sobre a circulação da informação, e se comprova que a informação que circula nas grandes camadas da população é a oral, obtida geralmente na Igreja e na Escola. A obtenção da informação, para a população carente, era de difícil acesso.

A multiplicação das escolas de biblioteconomia não foi um fator determinante de melhores condições para o acesso da população carente às fontes de informação. O profissional da informação, geralmente, não tinha condições de ser um propagador de uma política de leitura ou de propor metodologias adequadas para a interação da biblioteca com a comunidade.

De qualquer forma, principalmente as bibliotecas públicas dependeram muito da atuação do Instituto Nacional do Livro. Oliveira (1994) afirma que as políticas adotadas pelo Instituto Nacional do Livro, ao longo dos seus 52 anos de atuação, somaram contribuições expressivas e alguns percalços impostos ao desenvolvimento da biblioteca pública no Brasil.

A grande contribuição, segundo a referida autora, foi a contribuição para a incorporação da biblioteca pública à agenda governamental. $\mathrm{O}$ crescimento dos acervos e o apoio dado ao desenvolvimento da biblioteconomia no país também foram contribuições notáveis. Entre os erros, assinala a mencionada autora, estão a vinculação da política de bibliotecas à de promoção do livro, a falta de acompanhamento nas transformações ocorridas na sociedade brasileira e uma política conservadora, baseada em conceitos de cultura erudita, de elite (livro como tesouto intelectual, biblioteca como guardiã da cultura), e sua continuidade provocou a estagnação do trabalho da biblioteca.

A criação do Prêmio de Biblioteconomia e Documentação, o estágio remunerado para estudantes de biblioteconomia no atendimento às populações carentes, os carrosbiblioteca e caixas-estante, o sistema de co-edição, os cursos de treinamento intensivo e a obrigatoriedade de o prefeito incluir verba específica para manutenção da biblioteca pública também foram contribuições expressivas que o Instituto Nacional do Livro prestou ao desenvolvimento dos serviços bibliotecários no país.

Algumas dissertações e teses procuram justificar o fraco desempenho das bibliotecas públicas apontando para o processo de colonização, a ideologia dominante, livro e leitura como instrumentos de dominação, a ditadura militar e, mais recentemente, para o neoliberalismo. Na verdade, na procura dos erros para os próprios fracassos, devemos admitir que, se a biblioteca pública não teve o desenvolvimento esperado, isso se deve às dificuldades que o profissional da informação enfrentou para formar um público leitor, para elaborar diagnósticos consistentes, para vincular a biblioteca com os interesses comunitários e, principalmente, demonstrar a importância dos serviços bibliotecários para o grande público.

\section{O PAPEL DA BIBLIOTECA PÚBLICA NO CONTEXTO DA SOCIEDADE DA INFORMAÇÃO}

Para discutir o papel da biblioteca pública no contexto da sociedade da informação, devemos analisar previamente a representação social dos dois segmentos.

Com relação à sociedade da informação, devemos destacar que a maioria dos países já está consignando orçamento específico para a sua implantação. Alguns países privilegiam as questões tecnológicas; outros, as regiões desprovidas de infra-estrutura de comunicação e serviços bibliotecários. Há um crescimento da literatura sobre sociedade da informação, mas, na verdade, não há um crescimento do acesso à informação.

No final da década de 80 , especialistas afirmaram que a sociedade da informação seria uma sociedade voltada para o compartilhamento dos recursos e para o bem-estar social. As primeiras avaliações apontam que as desigualdades estão aumentando, e , na atualidade, os donos do poder são os donos dos meios de comunicação. 
A sociedade da informação traz no seu bojo as questões da globalização, das novas tecnologias e do modelo de desenvolvimento sustentável. Essas questões apresentam contrastes marcantes do ponto de vista social. Segundo Santos (2000), a globalização exige, de todos atores, de todos os níveis e em todas as circunstâncias, que sejam competitivos. Esse processo exige que empresas, instituições, igrejas e bibliotecas sejam competitivas. A competição acaba estimulando a violência (talvez o maior problema social da atualidade), porque a regra que vigora é a regra do resultado. Não existe ética. Quando, por exemplo, privilegia-se, no ensino secundário, a formação técnica, sem nenhum conteúdo humanístico, está se criando mais um fator que estimula atividades violentas. Além disso, devemos destacar que a globalização é um navio e o ingresso é conhecimento e informação, não há lugar para os analfabetos e para as pessoas que não apresentam mão-de-obra qualificada.

Para Fischmann (2000), as possibilidades trazidas pelas novas tecnologias são exemplificativas dos tempos em que vivemos. A ampliação de oportunidades de informação e de comunicação corresponde a aumento de sentimentos de impotência, de frustração e de inadequação. Tomamos consciência do quanto existe disponível e de nossa impossibilidade de absorver tudo que gostaríamos. Em buscar de aproveitar as oportunidades de informação e de novas formas de comunicação, vamos para o computador, acessamos a Internet e olhamos extenuados: como enfrentar esse oceano de informação que se nos apresenta? Mais fácil desistir. Não perdendo, é claro, a oportunidade de vivenciar sentimentos de impotência e ignorância. É interessante essa possibilidade que se apresenta ao ser humano: pode conhecer mundos antes inacessíveis e também entrar em contato com a própria ignorância.

Além disso, devemos destacar que as novas tecnologias produziram um usuário crítico e independente com relação aos serviços bibliotecários. Ele é mais crítico e independente, na medida em que sabe que a biblioteca não é a única fonte de informação, e às vezes, para obter informações precisas e com qualidade, tem de se utilizar novas tecnologias de informação.

No modelo de desenvolvimento sustentável, também um modelo altamente comprometido com resultados, é fácil observar que os problemas sociais aumentaram e que as verbas destinadas ao acesso à informação são extremamente ridículas. $\mathrm{O}$ preço do livro associado à falta de tempo e motivação para a leitura e obviamente a carência de bibliotecas públicas e escolares conduzem ao processo de desinformação. Parte expressiva da população brasileira ainda não tem noção de cidadania, ou mesmo de direitos e deveres, o que aumenta o desemprego e os problemas sociais.

O modelo de desenvolvimento sustentável se baseia em um governo trabalhando por objetivos e distribuindo o orçamento de acordo com os resultados alcançados. A área cultural, que historicamente deteve a menor fatia do bolo orçamentário, necessita, acima de tudo, receber recursos da iniciativa privada como a Lei Rouanet e a Lei de Incentivo à Cultura. Esses instrumentos de captação de recursos são mais utilizados na música, no cinema, no teatro, do que na biblioteca.

Nesse processo de globalização, de novos paradigmas tecnológicos e sociais e do modelo de desenvolvimento sustentável, caberá à biblioteca pública trabalhar no sentido de corrigir as deficiências do passado, como criar uma interação adequada com a comunidade e implantar produtos que de fato facilitem o acesso à Sociedade da Informação.

No prefácio do livro Biblioteca pública e informação à comunidade (Suaiden, 1995), o professor Antonio Agenor Briequet de Lemos pergunta: Para que servem as bibliotecas? Não é uma pergunta fácil de ser respondida na medida em que os profissionais da informação acreditam nos postulados teóricos disseminados ao longo dos cursos de graduação e pós-graduação. Mas, com certeza, a sociedade não terá as mesmas respostas dos profissionais da informação. Isso está claro no livro Conceito de biblioteca (Targino, 1984), pois a comunidade ou não sabe responder à pergunta acima formulada, ou responde com afirmações que nada têm a ver com as respostas dos bibliotecários.

$\mathrm{Na}$ verdade, os diversos segmentos da sociedade têm expectativas diferentes em relação ao papel da biblioteca pública. A indústria editorial acredita que o objetivo fundamental é a formação de um público leitor. Os educadores acreditam que a biblioteca deve ser o alicerce do processo ensino-aprendizagem. Os intelectuais acreditam que deve ser um espaço rico em literatura de ficção. $\mathrm{O}$ trabalhador comum não vê a biblioteca como um local para solucionar os problemas cotidianos.

A própria denominação "biblioteca pública" pressupõe uma entidade prestando serviços ao público em geral, independentemente das condições sociais, educacionais e culturais. Nesse aspecto, reside a grande falha da biblioteca pública, pois, até hoje, o único segmento da sociedade que é atendido parcialmente, em pequena proporção, é o dos estudantes de primeiro e segundo graus. 
$\mathrm{Na}$ batalha que trava para responder às inquietações da sociedade sobre o seu papel, a biblioteca pública perde cada vez mais prestígio e poder, deixando de ser o grande centro disseminador da informação, por tentar "ser tudo para todos".

A produção bibliográfica da área tenta apontar uma série de caminhos que possibilitem à biblioteca pública encontrar a sua verdadeira identidade como uma instituição eficiente na formação da cidadania e na melhoria da qualidade de vida da sociedade.

Suaiden (1980) realizou um levantamento das condições de 25 bibliotecas públicas estaduais. As conclusões revelaram que, na maioria, não havia profissionais qualificados, o acervo era deficiente e apenas um percentual mínimo da comunidade era atendido pela biblioteca. A grande massa da população, portanto os nãousuários, desconhecia a instituição, e as autoridades não encontravam razão para investir na biblioteca.

Em 1995, o mesmo autor, estudando as necessidades informacionais da população, propôs prioridades para a coleta e disseminação nas bibliotecas públicas de informação utilitária que ajudaria as pessoas a resolver os problemas cotidianos. Os estudos realizados demonstram que, para as populações carentes, a informação oral é até mais importante que a informação bibliográfica. À medida que a biblioteca pública decida implantar um serviço de informação utilitária, dará um grande passo, contribuindo para a formação da cidadania, e poderá se tornar um real centro disseminador da informação.

Na verdade, ainda são poucas as bibliotecas públicas que elaboram diagnósticos sobre as necessidades informacionais, estudos e perfil dos usuários. Nos Estados Unidos, esses estudos são freqüentes e colaboram para maior interação biblioteca e comunidade. Dois deles marcaram época, D’elia (1980) e Madden (1979).

O modelo confeccionado por D'Elia partia das seguintes variáveis como componentes da pesquisa:
a) características individuais dos usuário;
b) opinião e conhecimento dos serviços bibliotecários;
c) acessibilidade por parte dos usuários à biblioteca;
d) facilidade para utilizar a biblioteca;
e) utilização de outras bibliotecas.

Para levar a cabo essa investigação, D'Elia reuniu dados baseados em uma amostra de 442 números de telefones do catálogo de Syracuse (Estados Unidos). Dos 442 números selecionados, 61 não estavam em funcionamento, sobrando 322, se bem que somente 202 aceitaram participar da pesquisa. Estabeleceu-se então que seriam entrevistadas as donas de casa ou os indivíduos maiores de 18 anos. Dos entrevistados, 80\% foram caracterizados em função de três possíveis fatores:

a) utilização ou não da biblioteca;

b) freqüência de uso;

c) intensidade da utilização.

A freqüência de uso foi medida pelo número de vezes que os entrevistados iam a biblioteca, assim como pelo número de vezes que haviam telefonado para a biblioteca no ano anterior. A intensidade foi medida com base na duração da visita à biblioteca.

De acordo com o resultado da investigação, constatou-se que os usuários se diferenciavam dos não-usuários pelo freqüência com que acudiam aos acontecimentos culturais, assim como pelo seu nível de hábito de leitura.

Baseando-se em uma pesquisa sobre usuários e nãousuários de bibliotecas públicas dos Estados Unidos da América do Norte, Madden chegou às seguintes conclusões:

a) a utilização das bibliotecas está muito relacionada com outras atividades. Uma pessoa que realiza outras atividades, como política, desportos etc. é provavelmente usuário da biblioteca;

b) a mulher que não utiliza a biblioteca não participará seguramente de outros programas desenvolvidos por aquela. Seus interesses e atividades de grupo são muito limitados, e a biblioteca pouco lhe oferece, pois ela não tem intenção de variar e ampliar suas atividades cotidianas. Muitos bibliotecários contradizem essa conclusão, mas mostra-se evidente que a biblioteca não representa o aspecto principal da vida dessas pessoas;

c) muitos não-usuários poderiam ser conquistados por meio de grandes campanhas publicitárias, muito especialmente relacionados com aperfeiçoamento doméstico e carro-biblioteca. Muitos homens nãousuários poderiam se tornar usuários, desde que a biblioteca dissemine livros e serviços relacionados com os seus interesses;

d) os usuários assíduos da biblioteca possuem uma variedade de interesses tão grande, que as bibliotecas teriam dificuldades para definir suas necessidades. Por outro lado, os usuários representam uma pequena 
porcentagem do total da população, o que representa uma dúvida a respeito do emprego dos recursos em materiais destinados a este grupo;

e) os usuários moderados, de ambos os sexos, são um público que merece uma atenção especial. Cabe às bibliotecas organizar uma coleção dirigida aos anseios das aspirações da comunidade.

Portanto, à medida que a biblioteca periodicamente elabora diagnóstico representativo dos anseios da comunidade na área da informação, aumenta o grau de interação entre ambos, fortalecendo indicadores que vão possibilitar a elaboração de um planejamento estratégico. Geralmente o planejamento estratégico possibilita a execução de metas a curto, médio e longo prazo. No processo de tomada de decisão para a elaboração do referido planejamento, a comunidade - composta de usuários potenciais e reais - deve ter participação relevante.

Em um artigo publicado na Revista de Biblioteconomia de Brasília, Tarapanoff \& Suaiden (1995) fazem uma abordagem detalhada do planejamento estratégico das bibliotecas públicas brasileiras e demonstram que, devido a uma série de fatores, sendo o principal a falta de integração com a comunidade, houve um custo exagerado para pouco benefício no investimento em bibliotecas públicas. Outra conclusão importante do trabalho é a necessidade de conscientização social da comunidade - a formação para a cidadania - para que o usuário potencial, membro da comunidade, possa efetivamente entender e expressar as suas necessidades cotidianas e informacionais.

É importante entender que a sociedade brasileira passa por importantes transformações. A edição 1.426 da revista Veja, publicada em 10/01/96, demonstra, através de um convênio da Editora Abril com o Instituto Vox Populi, que o caráter do brasileiro mudou, sua avaliação é positiva e ele superou os mitos antigos do malandro cordial e do grande derrotado. Infelizmente, essas mudanças de comportamento, de hábitos e crenças não são utilizadas pelas bibliotecas públicas como parâmetros para modernização das atividades e vinculação com os novos tempos e conseqüentemente com a comunidade.

Além disso, devemos ressaltar que as bibliotecas públicas, inclusive para demonstrar o custo-beneficio dos produtos e serviços, devem se utilizar, cada vez mais, de metodologias e técnicas na interação com a comunidade. São muitas as técnicas de prospecção, sendo as mais recomendadas as seguintes: os cenários, monitoramento tecnológico, brainstorming e grupo focal. A técnica de cenários se utiliza para identificar tendências e observar variáveis, tais como o desenvolvimento das coleções, as necessidades de novos produtos e serviços, assim como o melhoramento das condições educativas e culturais da comunidade. A técnica de monitoramento tecnológico tem características particulares de observação de fatores científicos, telemáticos e tecnológicos que podem afetar a biblioteca pública e a comunidade. O brainstorming estimula respostas criativas em um grupo de pessoas com o fim específico de solucionar problemas gerados pela integração da biblioteca com a comunidade. Nessa técnica é importante compartilhar com a comunidade a tomada de decisão, principalmente nos momentos difícies como cortes orçamentários. No grupo focal, realizam-se entrevistas gravadas com técnicos, usuários, não-usuários e membros da alta hierarquia, mediante duas perguntas básicas: Como é a biblioteca hoje? Como deveria ser a biblioteca? A tabulação e análise dos resultados permitirá à biblioteca elaborar estratégias de acompanhamento do próprio desenvolvimento comunitário.

$\mathrm{Na}$ busca de um caminho que possibilite à biblioteca pública ser uma entidade expressiva na sociedade da informação, a segmentação de mercado representa a grande alternativa dos novos tempos. Philip Kotler (1995) desenvolveu investigações envolvendo a área de segmentação de mercado como uma forma de delimitar as áreas de interesses e, assim, tornar os serviços e produtos mais eficientes, ou seja, ao gosto da clientela. O chamado marketing de mercado-alvo necessita de três etapas principais. A primeira é a segmentação de mercado, o ato de dividir um mercado em grupos distintos de compradores, que podem exigir mix de produtos e/ou de marketing distintos. A empresa identifica maneiras diferentes para segmentar o mercado e desenvolver os perfis dos segmentos resultantes. A segunda etapa é o ato de desenvolver medidas de atração de segmentos e de escolher um ou mais segmentos de mercado em que vai atuar. A terceira etapa é o posicionamento do produto, o ato de estabelecer posicionamento viável competitivamente para a empresa e oferecê-lo em cada mercado-alvo. As características que deve possuir o segmento escolhido são exclusividade, exaustividade, verificabilidade e acessibilidade.

Basicamente, são três modelos de estratégia que podem ser utilizados pelos serviços de informação:

1. marketing indiferenciado: a biblioteca tenta atender a todos os segmentos do mercado, oferecendo a todos idênticos serviços e produtos. Esse geralmente é o modelo adotado pelas bibliotecas públicas brasileiras; 
2. concentração de mercado: a biblioteca concentra seus esforços somente em um segmento específico, proporcionando um excelente serviço em detrimento de outros segmentos considerados menos receptivos;

3. marketing diferenciado: a biblioteca estuda as características diferenciadas de cada segmento e prepara uma estratégia para atender às necessidades de cada um de maneira específica.

Portanto, segmentação de mercado é um processo que apresenta a definição de grupos homogêneos de clientes em função das seguintes variáveis: necessidades, desejos, características geográficas, demográficas e socioeconômicas.

No caso específico da biblioteca pública, justifica-se a utilização de técnicas de segmentação de mercado, pois os interesses informacionais da comunidade são heterogêneos e os recursos disponíveis nem sempre são suficientes para atender a esse tipo diversificado de demanda.

Para a seleção do segmento adequado, geralmente se utilizam duas variáveis; A primeira é a que se chama força organizacional, ou seja, os pontos fortes da biblioteca relacionados com o desenvolvimento das coleções, os recursos humanos e os produtos e serviços disponíveis para a comunidade. A segunda é a atração de mercado, que deve refletir sobre os pontos fortes do segmento a ser escolhido com os recursos disponíveis na biblioteca. $\mathrm{Na}$ medida em que as duas variáveis se cruzam e os pontos fortes são coincidentes, aquele segmento terá condições de ser viabilizado sem grandes esforços financeiros e humanos. Se os pontos fortes não coincidem, a biblioteca terá de realizar um esforço maior financeiro e de capacitação de recursos humanos para viabilizar a proposta de segmentação de mercado.

Com um projeto de pesquisa financiado pelo $\mathrm{CNPq}$, realizamos um trabalho de segmentação de mercado em um bairro composto de pessoas carentes no Distrito Federal. O segmento escolhido foi o das mães dos alunos do segundo ano do ensino fundamental. $\mathrm{O}$ segmento escolhido se justifica pela questão social e pelo fator multiplicativo, pois a idéia era também motivar o marido e os filhos. O diagnóstico apontou para as seguintes tópicos: bolsa-escola, aposentadoria, doenças sexualmente transmissíveis, oportunidade de emprego, documentos etc. As informações foram coletas e disponibilizadas de acordo com a capacidade intelectual do segmento escolhido. A melhoria da qualidade de vida foi o indicador mais relevante da avaliação final.
Portanto, à medida que a biblioteca pública se vincular adequadamente com a comunidade, ela passará a ser o caminho que possibilitará a participação efetiva na sociedade da informação. Isso é de extraordinária importância em um país onde a desinformação atinge altas proporções, e, sem essa oportunidade, milhares de pessoas jamais terão oportunidade de entender e de ter noção dos seus direitos e deveres em uma sociedade globalizada, pois o acesso à informação, nos novos tempos, significa o investimento adequado para diminuir as desigualdades sociais e as formas de dominação que foram dominantes na história contemporânea.

\section{REFERÊNCIAS BIBLIOGRÁFICAS}

1. ANDRADE, Mário. Bibliotecas populares. Revista Livro, v. 2, n. 5, p. 7, 1957.

2 BAMBERGER, R. Como incentivar o hábito de leitura. São Paulo : Cultrix, 1977. $117 \mathrm{p}$.

3. D'ELIA, G. P. M. Development and testing of a conceptual model of public library user behavior. Library Quarterly, n. 50, p. 410-430, oct. 1980.

1. FISCHMANN, Roseli. Fragmentos tecnológicos. Correio Braziliense, Brasília, 4 set. 2000. p. 5.

2. KOTLER, Philip. Administração de marketing: análise, planejamento, implementação e controle. São Paulo : Atlas, 1995. 848 p.

3. LiMA BARRETO, A. H. Triste fim do Policarpo Quaresma. São Paulo: Brasiliense, 1976

4. MADDEN, M. Lifestyles of library user and nonuser. [s. 1.] : University of Illinois. Graduate School of Library Science, 1979. 44 p. (Ocasional papers, 137)

5. OlIVEIRA, Zita Catarina Prates. A biblioteca fora do tempo; politicas governamentais de bibliotecas públicas no Brasil, 1937-1989. 1994. Tese (Doutorado) - Universidade de São Paulo, São Paulo, 1994.

6. SANTOS, Milton. Entrevista. Jornal do Brasil, Rio de Janeiro, 27 ago. 2000.

7. SUAIDEN, Emir J. Biblioteca pública brasileira; desempenho e perspectivas. São Paulo : Lisa, 1980.

8. SUAIDEN, Emir J. Biblioteca pública e informação à comunidade. São Paulo : Global, 1995. 112 p.

9. TARAPANOFF, Kira, SUAIDEN, Emir. Planejamento estratégico de bibliotecas públicas no Brasil: histórico, crise e perspectivas. Revista de Biblioteconomia de Brasília, Brasília, v.19, n.2, p.137-164, jul./dez. 1995.

10. TARginO, M.G. Conceito de biblioteca. Brasília : Associação dos Bibliotecários do Distrito Federal, 1984. 